\title{
A Prospect Approach to Option Pricing
}

\author{
Cokki Versluis \\ Faculty of Economics and Business Administration, Maastricht University, \\ P.O. Box 616, 6200 MD Maastricht, The Netherlands \\ Thorsten Lehnert * \\ Limburg Institute of Financial Economics (LIFE), Maastricht University, \\ P.O. Box 616, 6200 MD Maastricht, The Netherlands \\ Nijmegen School of Management, Radboud University Nijmegen, \\ P.O. Box 9108, 6500 HK Nijmegen, The Netherlands \\ Christian C.P. Wolff \\ Limburg Institute of Financial Economics (LIFE), Maastricht University, \\ P.O. Box 616, 6200 MD Maastricht, The Netherlands
}

This version: November 2007

\begin{abstract}
It's a well known empirical fact that actual option prices show persistent and systematic deviations from Black-Scholes option values. While a substantial number of enhancements have been proposed in the literature, these approaches typically leave investor's preferences towards risk unmodified. Recently, empirical studies using option prices find support for non-concave utility functions proposed by Kahneman and Tversky. In this paper, we study option prices in an economy where investors are loss averse over fluctuations in the value of their financial wealth. The design of our pricing model is influenced by prospect theory, including behavioral aspects like risk attitude, mental accounting and probability perception. The theoretical marginal prospect option writer is risk averse in the domain of gains, risk taking in the domain of losses; (s)he overestimates small probabilities and underestimates large probabilities of the option being exercised in-the-money. The pricing framework can help to explain the implied volatility pattern typically observed from actual option prices. Empirical analysis on European call options on the S\&P 500 index shows that prospect option pricing models significantly improve the fitting performance in in-sample, as well as in out-of-sample analysis. Further, the analysis shows that the marginal investor's behavior is different from the prospect theoretical observations. In stead of being risk averse in the domain of gains, risk taking in the domain of losses, and overestimate small and underestimate large probabilities of the option expiring in-the-money, marginal writers of call options on the S\&P 500 index display the reverse behavior.
\end{abstract}

JEL Codes: D01, G11, G12.

Keywords: Prospect Theory, Framing, Mental Accounting, Risk attitude, Loss aversion, Probability perception, Weighting function, Option Pricing.

* Correspondence to: Tel: +31-43-3883838; Fax: +31-43-3884875. E-mail: t.lehnert@,finance.unimaas.nl. 


\section{Introduction}

Pricing behavior in financial markets has traditionally been explained by assuming rational investors. They correctly update their beliefs when they receive new information and given their beliefs they make choices, which maximize their expected utility. In the past couple of decades, however, the finance literature has amassed a substantial number of observations of apparent anomalies with respect to expected utility theory. The possibility that some market participants behave less than rational has been considered and as a consequence prices might deviate from those predicted by the expected utility framework ${ }^{1}$. During the 1990 s, finance literature started to re-explore psychological concepts to explain the behavior of market participants as a separate field of research. Most of the behavioral finance research has been focused on stock markets and attempts to explain among others phenomena like under- and overpricing, hypes and panic, premium between risky and risk-free assets, preference for cash dividends and the tendency to sell winning stocks rather than losing stocks. Overviews of the various aspects of behavioral finance have been given by Barberis and Thaler (2003), Goldberg and von Nitzsch (2001), Shefrin (2002), Shiller (1999) and Thaler (2005). Within the traditional finance paradigm, the most frequently used model to determine the value of options is based on the theory of Black and Scholes (1973). This theory is based on a riskless portfolio of stocks and a call option on that stock. It is observed that prices of traded options systematically do deviate from the value calculated by the Black-Scholes theory (for an overview, see Mayhew, 1995). One explanation for this deviation is to question the assumptions of the theory. Another explanation is based on the fact that the Black-Scholes portfolio is not riskless (Omberg, 1991) and therefore behavioral aspects of (potential) option investors do interfere with the pricing process of an option.

At the empirical level, several studies have shown that option valuation models with conditional heteroskedasticity and negative correlation between volatility and spot returns capture the particular mispricing pattern and significantly improve upon the performance of the BlackScholes model. The discrete-time GARCH option pricing model has shown to be a flexible, empirically successful model (see among others Heynen, et al (1994), Duan (1996) and Heston and Nandi (2000)). Recently, an increasing number of simulation and numerical methods for this class of option pricing models become available (see Duan and Simonato (1998), Ritchken and

\footnotetext{
${ }^{1}$ Interestingly, the basic idea was already launched as early as 1759 in Adam Smith's book about "The Theory of Moral Sentiments" (Nava, Camerer and Loewenstein, 2005).
} 
Trevor (1999), Heston and Nandi (2000) and Duan et al. (2001)). Using a generalized GARCH option-pricing framework, Lehnert (2003) showed that conditional leptokurtosis and skewness reinforces the effects of conditional heteroskedasticity and asymmetry in the volatility process. His GARCH option pricing model driven by skewed generalized error distributed innovations outperforms the closed-form GARCH option pricing model of Heston and Nandi in-sample as well as out-of-sample. The improvements in pricing errors are particularly pronounced for outof-the money put and call options, while the model partly underperforms the Gaussian model for near-the-money options. The results are in line with recent results obtained by Christoffersen et al. (2006). While they demonstrate the importance of conditional skewness and jumps for the pricing of out-of-the-money puts, their closed-form Inverse Gaussian GARCH option pricing model significantly underperforms a standard Gaussian model for several other types of options. Therefore, the empirical evidence does not necessarily suggest that e.g. modeling jumps in returns and volatility is the appropriate approach for the purpose of option valuation. In recent years, it becomes apparent that the mispricing for some types of options is only marginally improved, but those models cannot adequately account for the particular pattern observed in option prices.

On a less sophisticated level, partitioning of volatility with respect to moneyness and maturity also diminishes the mispricing of options with the Black-Scholes model significantly (Dumas et al. (1998)). They propose so-called implied volatility functions to capture the observed implied volatility surface of traded options, but do not give any behavioral explanation. As volatility is related to the underlying asset and not to a specific option series, it should be concluded that either the assumption in the Black-Scholes theory that the underlying is a geometric Brownian process is not correct or that investors hold different preferences for different option series. If we consider the first explanation with respect to stocks and indices, then it might be true that volatility is dependent on maturity because future return distributions of short horizon are generally leptokurtic, while higher horizon returns are normally distributed (Fama, 1965). It is therefore hard to imagine that volatility will have an effect on the actual prices within an option series of equal maturity with a longer horizon than one month. Therefore in this paper, we will focus on the second explanation, the one that assumes that deviations between actual option price and Black-Scholes model predicted value are due to behavioral aspects. 
The first 'behavioral' explanation of option pricing is due to Shefrin and Statman (1993). They assumed prices of covered calls in a one period binomial setting and compared value function $^{2}$ modified option prices with prices from the CRR model (Cox, Ross and Rubinstein, 1979). Particularly Shefrin and Statman focused on the writing of covered calls: writing call options on stock in possession and concluded that its perceived value and consequently the choice from it, is highly dependent on the parameters of the value function. The prospect theory expected value of the covered call position exceeds the prospect theory expected value of the stock-only position for investors who are sufficiently risk-averse in the domain of gains ${ }^{3}$.

Shefrin and Statman do not consider the weighting function of the prospect theory. However, according to Shiller (1999) it is particularly the weighting function that may explain mispricing of options. Breuer and Perst (2004) included a (competence modified) weighting function to determine the prospect value of discount reverse convertibles (DCRs). DCRs can be interpreted as a combination of a risk free asset with a short position in put options. Prospect values based on the Tversky-Kahneman values for its parameters, are compared with the Black-Scholes model in a multi period continuous time setting. Breuer and Perst conclude that investments in risk free assets are preferred in low drift stock markets; in higher drift stock markets the investment in stock is preferred, while in medium drift stock markets DCRs are preferred with low volatility and risk free assets with higher volatility prediction for the price of the stock.

Using the same set of parameter values for all agents suggests that they have the same attitude towards gains and losses. In their experimental study based on a one period binomial CRR estimation problem, Abbink and Rockenbach (2005) find a remarkable difference in the option pricing behavior of professional traders and students. Investors are assumed to follow an option valuation strategy with a separating price and will buy the option whenever the option price is lower than the separating price and will sell the option if the option price is higher than the separating price. At small probabilities professional traders have a significantly higher separating prices compared to students. At large probabilities both traders and students have equivalent separating prices, which are higher than the separation price at low probability. Their results suggest that it remains questionable whether it is realistic to generalize Tversky-Kahneman results with respect to the values of the parameters to real world trading processes.

\footnotetext{
2 The authors consider the Tversky and Kahneman (1992) type of value function.

${ }^{3}$ De Groot and Dijkstra (1996) re-analyzed value function modified covered calls in a dynamic setting using monthly returns on a Dutch equity index and came largely to the same conclusion as Shefrin and Statman.
} 
Also in 'markets' that are not liquid, like investment projects, specific behavioral biases affecting the subjective valuation of (real) options have been reported. Howell and Jägle (1997) show that managers' assessments of real options tend on average erratically deviate from the normative Black-Scholes model. Miller and Shapira (2004) find that buyers and sellers price options below their expected values with buyers' prices consistently below sellers' prices.

Another way of looking at the behavioral aspect of option pricing is based on agent theory in which economic agents behave according specified beliefs and therefore have different views about the value of a proposed proposition. Guo (1998) considered two agents with different expectations with respect to the values of the parameters of the underlying geometric Brownian price process and was able to perfectly fit prices of call options on the S\&P 500 index. The parameter values of the two agents from his analysis, however, are so far apart, that it is questionable whether these agents are representative for real world traders. Another two agent model due to Benninga and Mayshar (2000) shows that different expectations with respect to relative risk aversion might be another explanation for the observed mispricing of options.

In a recent paper, Poteshman and Serbin (2003) analyze the early exercise of Chicago Board Options Exchange listed call options by different classes of investors over the 1996-1999 period. They find support that there are a large number of early exercises that can be identified as clearly irrational without invoking any model of market equilibrium, and these exercises are not uniformly distributed across the investor classes. Irrational exercise is triggered both by the underlying stock price attaining its highest level over the past year and by the underlying stock having high past returns. Their findings provide evidence that prospect theory is operative in the options market and that it applies differentially across various classes of investors. In a related study, Blackburn and Ukhov (2006) investigate the shape of investor's utility function. Using options on the stocks in the Dow Jones Index, they find support for non-concave utility functions with reference points as proposed by Kahneman and Tversky. The evidence for Kahneman and Tversky Prospect Theory value function is much stronger than the support for the standard concave utility function.

In this paper, we study option values in an economy where investors are loss averse over fluctuations in the value of their financial wealth. The design of our pricing model is influenced by prospect theory, including behavioral aspects like risk attitude, mental accounting and probability perception. Using prospect theory allows us to simplify a problem into mental accounts. 
Rockenbach (2004) compares three different mental accounts with the CRR model in a one period dichotomy setting and concludes that in a controlled classroom experiment mental accounts are a more realistic explanation of price estimation behavior than the CRR model, indicating the importance of mental accounting in the pricing of options.

The paper is organized as follows. Section 2 introduces three important concepts relevant to the behavioral aspects of option pricing: 'framing', 'mental accounting' and 'prospect theory'. In the next section, the concepts are applied to option pricing to establish a model to estimate marginal prospect-based prices. A numerical example is provided to highlight the effect of different degrees of prospect behavior on option prices. Section 4 deals with an empirical analysis of European call options on the S\&P 500 index, including prospect-based option pricing and pricing based on elements of the prospect theory. Finally we will wrap up with a conclusion section.

\section{Behavioral aspects of option pricing}

\subsection{Framing}

Framing refers to the way a problem or proposition is presented. It is therefore objective to the subjects that take decisions based on the presented problem or proposition. In other words all subjects face the same setting within which the problem or proposition is being described. The presenter of the problem has the choice how to frame the problem; another presenter might frame the problem differently. An example of framing, based on Tversky and Kahneman (1986) is the well known Müller-Lyer illusion shown in Figure 1.

\section{[Figure 1]}

If frame 1 is presented with the question which of the horizontal lines is longer, then generally $\mathrm{A}$ is selected while B is actually longer. If the problem is presented as shown in frame 2 , the overwhelming majority selects B as being the longer line. This simple example shows that the way the problem is framed is of utmost importance to final valuation and choice.

With respect to option pricing or subjective option valuation one can frame propositions as one period dichotomy prospect, multi period dichotomy prospect, prospects with continuous outcomes or based on the actual options market data. One period dichotomy prospects are gener- 
ally used in controlled laboratory experiments. They, however, have the drawback of being oversimplified and might be interpreted as a lottery rather than as the outcome of the actual dynamic processes of the stock market. Option traders interpret probabilities differently when exposed to a risky project, where objective probabilities are known or to uncertain prospects, where a subjective assessment of probabilities is required (Fox, Rogers and Tversky, 1996).

\subsection{Mental accounting}

Mental accounting attempts to describe the process whereby people code, categorize and evaluate economic outcomes. Mental accounting theorists argue that people group their assets into a number of non-fungible mental accounts or mental compartments (Thaler, 1980, 1985, 1999; Tversky and Kahneman, 1981). The decision process consists of two stages: editing and evaluation. In the first stage, people breakdown complex problems into simpler sub problems (Kahneman and Tversky, 1979; Tversky and Kahneman, 1981). In doing so, they apply rules of thumb, or heuristics, that facilitate the interpretation of the various possibilities from which they have to choose. After the various prospects have been edited and categorized, they are evaluated in the second stage of the decision process. The prospect with the highest value is chosen. The rules of thumb when editing and evaluation are necessarily a simplification.

Mental accounting is a subjective process. In other words, it is the interpretation of economic propositions by individuals or groups. The human mind simplifies the real world problem. Therefore mental accounts are generalizations and they tend to be as simple as feasible. Confusingly the editing stage of the mental accounting process is also called the framing stage. In this paper we will refer to 'framing' as the way the problem is presented and to 'mental accounting' as the way the problem is subjectively interpreted.

There may be a range of potential mental accounts for any particularly framed problem. First of all it is dependent on the way the problem is framed. Obviously, if the decision taker is presented a complex problem he will probably use a different way of mental accounting than if he is presented with a simple problem. For instance, if an option valuation proposition is presented in a dynamic continuous world the creation of a mental account is much more difficult than if the problem is presented as a dichotomy one period proposition. If we consider for exam-

ple the Müller-Lyer illusion presented in section 2.1 then the answer is clearly dependent on the frame in which it is presented. 
The decision taker determines the relevant subject-matter of the problem in order to simplify the problem based on his prior knowledge and experiences. If we again consider the Müller-Lyer illusion and we assume that frame 1 is being presented, then - with no prior knowledge of the Müller-Lyer illusion - the mental account is equivalent to the presentation presented in frame 1. On the other hand, if the decision taker has previous knowledge about the MüllerLyer illusion - by for example being a psychology student - his/her mind will create a mental account similar to the presentation in frame 2. This example shows the creation of a mental account might be depending on previous experiences.

Previous experience is also important in valuing option related problems. A scholar that is well familiar with the Black-Scholes theory values an option by applying the Black-Scholes model, while individuals with no prior Black-Scholes theoretical knowledge value an option by other (heuristic) means, for instance by considering the future density function of the price of the underlying asset or by considering potential cash flows. Substantial differences in estimation behavior of option values have been noticed between traders and students (Fox, Rogers and Tversky, 1996; Abbink and Rockenbach, 2005). This experience-based estimation seems to be in line with competence modification of the weighting function from prospect theory (Kilka and Weber, 2001).

A breakdown of mental accounts into different type of assets or potential propositions of different risk class has been noted. There is a tendency to view economic propositions as individual investments rather than considering the whole portfolio in the decision process (Fisher and Statman, 1997; Shefrin and Statman, 2000). This phenomenon has been called 'narrow framing' by Thaler and he further proposes that from a potential set of mental accounts with different segregation level, generally the most attractive one is chosen (Thaler, 1985). Thaler calls this decision process 'hedonic framing', which might be a helpful guide explaining how people value propositions (Thaler, 1999). Even when an individual uses a 'narrow framing' mental account, there are several possibilities to segregate. Considering options, one might view naked options versus options in combination with its underlying asset: segregation related to the entities considered. Or one might aggregate or segregate current cash flows versus future cash flows, segregation with respect to time. In this paper we will consider prospect theoretical option values in a time segregated narrow frame mental account setting. 


\subsection{Prospect theory}

In 1979, Kahneman and Tversky launched their prospect theory in what in retrospect showed to be a seminal paper. On the basis of experiments conducted among colleagues and students, they concluded that the theory of expected utility maximization does not hold in practice. According to Bernstein (1996), one of the corner stones of prospect theory is the cognitive difficulty to fully understand the subject matter, as nature is so complex that it is hard to draw valid generalizations from what we observe. Tversky and Kahneman showed that when subjects are asked to solve a range of choice problems, they evaluate cash flows by gains and losses in an asymmetric way. In situations of winning people were risk averse, while in situations of losing they were riskseeking. The experiments also showed that respondents are more sensitive to losses than to gains (loss aversion). Another important part of prospect theory is the finding that people's subjective probabilities do not correspond to objective probabilities. These behavioral aspects are reflected by the parameters, risk attitude (risk-averse or risk-seeking), loss aversion and weighting function (Tversky and Kahneman, 1992). Moreover risk attitude, loss aversion and perceived probability might be dependent on the subject's recent cash flow history. After experiencing a financial gain subjects can increase their willingness to accept risks, while prior losses can decrease the willingness to take risks (Thaler and Johnson, 1990). According to Barberis, Huang and Santos (2001), investors become less sensitive to losses after prior gains due to a shift of the reference point of the value function to a lower value. Conversely, after a prior loss investors become more loss averse. In this paper we will apply prospect theory including the perception of probabilities in a static rather than a dynamic setting. However, the pricing framework can be easily extended into a dynamic setting.

\section{The Pricing Framework}

In the dichotomy representation of the prospect theory, there are two possible outcomes with related probabilities. The value of such a prospect is based on a value function $(v)$ and a weighting function $(w)$. The value function is attached to the value of an outcome $(x)$ and the weighting function to the probability of that outcome $(q)$. For a prospect with a nonnegative $\left(x_{1}\right)$ and a negative outcome $\left(x_{2}\right)$ and corresponding probabilities $q_{1}$ and $q_{2}$, we get

$$
V=w^{+}\left(q_{1}\right) v^{+}\left(x_{1}\right)+w^{-}\left(q_{2}\right) v^{-}\left(x_{2}\right)
$$


with the superscript '+' being valid for nonnegative outcomes and the superscript '-' for negative outcomes.

The value function is typically given by

$$
v(x)=\left\{\begin{array}{l}
x^{a}, x \geq 0 \\
-\lambda(-x)^{b}, x<0
\end{array}\right.
$$

with $a$ and $b$ being constants determining the curvature of the value function in the domain of gains and losses, respectively. $\lambda$ controls for the so-called loss aversion and values larger than one imply that negative outcomes are perceived to be more painful than positive outcomes of the same magnitude. The weighting function is typically given by

$$
w(q)=q^{\gamma} /\left[q^{\gamma}+(1-q)^{\gamma}\right]^{1 / \gamma}
$$

with $\gamma$ being a constant that controls for the over- and underweighting of small and large probabilities.

The price of an option is the outcome of its perceived value by investors. In equilibrium, the marginal investor determines the price. We assume that the marginal investor prices the option according to the valuation of the prospect theory in a time and entity segregated narrow framing mental account. Lets consider the marginal investor is writing a European style call option on a non-dividend paying stock or index. Two possible states will exist at the time of expiration $(t=T)$. The first one is: if the price of the underlying asset is higher than the exercise price $\left(S_{T}>K\right)$, the option will be exercised. The probability of being exercised $(q)$ is given by

$$
q=\int_{K}^{\infty} f\left(S_{T}\right) d S_{T}
$$

with $S_{T}$ being the price of the underlying asset at expiration, $K$ being the exercise price and $f\left(S_{T}\right)$ being the probability density function of $S_{T}$. The expected value (conditional on exercising the option), denoted by $x$, is then equal to

$$
x=-\int_{K}^{\infty}\left(S_{T}-K\right) f\left(S_{T}\right) d S_{T} / q
$$

The second state is the reverse of the first one: the price of the underlying asset is lower than the exercise price $\left(S_{T} \leq K\right)$ and the option will not be exercised. The probability that the option is not 
exercised is equal to (1-q) and its pay-off is zero. Therefore, in the case when the option writer is evaluating the option, $x$ can be considered to be a loss and Equation 1 can be simplified to

$$
V=w^{-}(q) v^{-}(x)
$$

In addition to the potential negative pay-offs at $t=T$, the writer receives a premium at $t=0$, denoted by $c$. Assuming that we can invest the cash amount $c$ at the risk-free interest rate $\left(r_{f}\right)$, its future value is equal to $c \exp \left(r_{f} T\right)$. In equilibrium the prospect value of the invested cash amount $c$ should be equal to the prospect value of $x$

$$
v^{+}\left(c \exp \left(r_{f} T\right)\right)+w^{-}(q) v^{-}(x)=0
$$

Substituting the value functions from Equation 2 into Equation 7 gives the option value as

$$
c=\exp \left(-r_{f} T\right)\left(w^{-}(q) \lambda(-x)^{b}\right)^{1 / a}
$$

We can determine $x$ and $q$ if the underlying price process is known. Assuming a geometric Brownian price process with drift $\alpha$ and volatility $\sigma$, then the future density function of the price of the underlying asset is

$$
f\left(S_{T}\right)=\exp \left(-\left[\ln \left(S_{T} / S_{0}\right)-\left(\alpha-\sigma^{2} / 2\right) T\right]^{2} / 2 \sigma^{2} T\right) / S_{T} \sigma \sqrt{2 \pi T}
$$

With the Equations 4, 5 and 9, $q$ and $x$ are determined as

$$
q=\Phi\left(\delta_{-1}\right)
$$

and

$$
x=K-S_{0} \exp (\alpha T) \Phi\left(\delta_{1}\right) / \Phi\left(\delta_{-1}\right)
$$

with $S_{0}$ being the current price of the underlying asset and $\Phi\left(\delta_{m}\right)$ the cumulative standard normal distribution of $\delta_{m}$, defined by

$$
\delta_{m}=\left\{\ln \left(S_{0} / K\right)+\left(\alpha+m \sigma^{2} / 2\right) T\right\} / \sigma \sqrt{T}
$$

Substituting the Equations 10 and 11 into Equation 8 gives the value of the segregated narrow framed call option from the writers' point of view as

$$
c=\exp \left(-r_{f} T\right)\left(\lambda w^{-}\left[\Phi\left(\delta_{-1}\right)\right]\left[S_{0} \exp (\alpha T) \Phi\left(\delta_{1}\right) / \Phi\left(\delta_{-1}\right)-K\right]^{b}\right)^{1 / a}
$$

with $\delta_{m}$ being defined in Equation 12 and $w$ being defined in Equation 3. In a similar way the value of a segregated narrow framed put option can be derived. 


\section{Numerical example}

In order to demonstrate the effect of non-concave utility functions, loss aversion and probability perception on the price of an option, we show option values under different prospect parameters in relation to changes in the strike price. We define 'prospect sentiment' as the deviation of investor behavior from the standard expected utility framework. It is assumed that the fundamental value is captured by the option value according to the Black-Scholes theory. Suppose that the Black-Scholes parameter values are $S_{0}=100, \alpha=0.1, r_{f}=0.1, \sigma=0.2$ and $T=1$. We consider three levels of prospect sentiment:

- Zero prospect sentiment (linear value function, no loss aversion and no over/underestimation of small/large probabilities) referring to option values based on the Black-Scholes theory with prospect parameters $a=1, b=1, \lambda=1$ and $\gamma=1$;

- Prospect sentiment, based on the observations from prospect theory that investors are risk averse for gains (concave value function), risk taking and loss averse for losses (convex value function), overestimating small probabilities and underestimating large probabilities. The prospect parameter values are based on experimental evidence by Tversky and Kahneman (1992): $a=0.88, b=0.88, \lambda=2.25$ and $\gamma=0.61$;

- Moderate prospect sentiment including the observations from prospect theory, but with parameter values reflecting only $10 \%$ of the Tversky-Kahneman prospect sentiment: $a=0.988, b=0.988, \lambda=1.125$ and $\gamma=0.961$.

Prospect option prices with respect to changes in strike price are given in Table 1.

[Table 1]

Moderate prospect sentiment gives slightly increased prices in the order of $11 \%$ compared to the Black-Scholes reference. Tversky-Kahneman parameter values based prospect sentiment gives substantial higher prices of about a factor two compared to prices according to the Black-Scholes theory. The higher prices under prospect sentiment increase the implied volatility as being calculated by the Black-Scholes option valuation formula as shown in Figure 2. This effect is consistent with observations made by Fleming, Ostdiek and Whaley (1995) and Christensen and Prabhala (1998) that implied volatilities of short-term at-the-money equity index options are on average higher than the realized volatilities over the option's life. 
[Figure 2]

The increase is most pronounced at low strike prices resulting in a pronounced volatility skew (or smirk). The pattern is well known for options on stocks and stock indices, particularly after the market crash of '87, where out-of-the-money put options (and therefore in-the-money calls) are typically overpriced relative to at-the-money options (see for example Rubinstein, 1994). In our model, three effects lead to a mispricing of options; the most important one being loss aversion. Assuming a writer of an in-the-money call option, an upward movement in the stock price would be much more painful for him than a downward movement due to loss aversion. For out-of-the-money call options the effect is additionally based on the possibility that the option might become in-the-money and the buyer would exercise the option. Consequently, the writer would increase the implied volatility in order to be compensated for that. However, given the lower delta of out-of-the-money calls, the effects are less pronounced compared to the in-themoney calls. Additionally, the more pronounced the prospect sentiment, the steeper the implied volatility curve. The implied volatility plot under moderate prospect sentiment is equivalent to the pattern observed with actual option prices. The Tversky-Kahneman based prospect sentiment results in a shape that is too extreme compared to a pattern implied out from actual market prices.

As a further analysis, we consider the derivatives of the option price with the parameters of the Black-Scholes model, typically referred to as the 'Greeks' (Table 2).

[Table 2]

In general, absolute sensitivities increase with increasing prospect sentiment, except for vega. Given our prospect option pricing model, we derive two interesting results: Firstly, vega is positive under the no prospect sentiment assumption, but becomes increasingly negative with increasing prospect sentiment for in-the-money-call options. Therefore, an increase in volatility would reduce the call option price. At high strike prices (out-of-the-money call options) we notice the increasing positive sensitivity at increasing prospect sentiment. This is due to the fact that our weighting function is modifying the perception of small and large probabilities. Sec- 
ondly, for deep in-the-money calls, delta becomes greater than one, even for moderate prospect sentiment. Therefore, the increase in the call option value is larger than the increase in the price of the underlying. At first glance this seems a puzzling result, but interestingly, both effects have already been documented in an empirical study of Bakshi et al. (2000). They empirically analyze some basic properties shared by all standard Black-Scholes type option pricing models. Using S\&P 500 options, they find that implications of one-dimensional diffusion option models are not completely consistent with observed option price dynamics. Their results are valid even after controlling for time decay and market microstructure effects. The design of our pricing framework can partly help to explain their empirical results.

Additionally we consider the sensitivities with respect to the Tversky-Kahneman parameters (Table 3).

[Table 3]

More risk averse behavior in the domain of gains (in this case smaller values for $a$ ) leads to higher call option prices, while more risk taking in the domain of losses (in that case smaller values for $b$ ) lead to lower call option prices. The more pronounced the risk attitude, the more pronounced the effect. A similar effect can be observed for the loss aversion parameter. The more loss avers the option writer (larger values for $\lambda$ ), the higher the call option price. An upward movement in the stock price would be much more painful than a downward movement, and with increasing loss aversion the impact on the option price becomes stronger. In general, absolute sensitivities decrease from in-the-money calls to out-of-the-money calls, except for the sensitivity with respect to $\gamma$. The more the option writer overestimates small probabilities (the smaller $\gamma$ ), the lower the option price for in-the-money calls, but the higher the option price for (deep) out-of-the-money calls, given zero or moderate prospect sentiment. The call option writer is loosing money, if the out-of-the-money call is getting in-the-money and will be exercised. This will only happen with a small probability, but the more (s)he overestimates small probabilities (the smaller $\gamma$ ), the larger the value (s)he is asking for the out-of-the-money call. Interestingly, increased overestimation of small probabilities has a larger negative effect on the option price for near in-the-money calls than for deep in-the-money calls. This is due to the particular shape of the weighting function. 


\section{Empirical analysis}

We test the prospect option pricing model with end-of-the-day S\&P 500 European options (SPX) premiums supplied by the CBOE. We opt to use data of 2002 and 2006, respectively being the year with the highest (26.1\%) and being the year of the lowest realized volatility of the S\&P 500 $(10.1 \%)$ in the ten year period from 1996 to 2006. Low volume option series with a volume less than 10 contracts per day have been ignored in the analysis. In addition to the prospect model we analyze also partial prospect pricing models including only one element of the prospect pricing model and we will refer to those models as 'expected value' (EV), 'value function' (VF) and 'weighting function' (WF). As reference we use the Black-Scholes model with constant implied volatility (BS) for all option series of one particular day. The relation between the parameters of the various models is shown in Table 4. We notice that the BS model is nested in the EV, VF and WF models and that all those models are nested in the prospect model.

[Table 4]

We perform an in-sample and an out-of-sample analysis. In the in-sample analysis, the parameters of the models are estimated at minimum weighted root mean squared error (wRMSE) by the Newton steepest descent method. The wRMSE is volume weighted and determined by

$$
w R M S E=\sqrt{\frac{\sum_{i=1}^{n} v_{i}\left(c_{i}-c_{i, \mathrm{model}}\right)^{2}}{n \sum_{i=1}^{n} v_{i}}}
$$

with $\mathrm{c}_{i}$ being the actual option premium, $c_{i \text {,model }}$ being the premium predicted by the model, $v_{i}$ being the daily trading volume and $n$ being the number of options of a particular trading day. All prices are given in US dollars.

The average S\&P 500 index is 994 in 2002 and 1310 in 2006. US weekly rates provided by Datastream have been used as risk-free rates of return. The average risk-free rate of return is $1.8 \%$ in 2002 and $5.0 \%$ in 2006 . The call price data is broken down into time to maturity intervals and moneyness intervals, in line with the analysis by Christoffersen, Heston and Jacobs (2006). Moneyness $(M)$ is being defined as 


$$
M=K / S_{0} \exp \left(r_{f} T\right)
$$

Table 5 gives an overview of the number of observations and Table 6 gives an overview of the average call prices.

\section{[Table 5]}

[Table 6]

The maximum number of observations lies around at-the-money options. The number of observations decreases with increasing time to maturity. Out-of-the-money option series are more frequent for the year 2002 compared to the year 2006 (on a relative basis). The analysis includes a wider range of moneyness intervals compared to the Christoffersen-Heston-Jacobs analysis. As a consequence also the range in option prices is wider.

It is difficult to compare the option prices of 2002 with the 2006 prices as volatility, price of the underlying asset and risk-free rate of return are different for these years. Taking the difference between the option prices of the various option moneyness classes of year 2002 minus year 2006 shows that at time to maturity of less than 80 trading days, the 2002 in-the-money options are lower priced than the 2006 in-the-money options (see Figure 3). For time to maturity of more than 180 trading days the option prices of 2002 are higher than the 2006 option prices. We have included the actual differences in option prices with the one predicted by the Black-Scholes model with average realized values for volatility, price of the underlying asset, risk-free rate of return and time to maturity into Figure 3. The differences for the model predicted prices are larger than the differences in actual option prices, especially for time to maturity of more than 20 trading days, which strongly indicates mispricing between model predicted and actual prices.

\section{[Figure 3]}

\section{Estimating the models using option prices (in-sample analysis)}

The parameters of the various models have been estimated at minimum weighted root mean squared error. Parameter values and weighted root mean squared error are given in Table 7. The fit of all models is better in the low volatility year (2006) compared to the high volatility year (2002). Judged by wRSME the nested models obviously have a poorer fit with the experimental 
data. The models that include an element of the prospect theory are not nested. Of those models, the VF model gives the best fit, followed by the WF model and then by the EV model. Penalizing the models for the number of implied parameters by Akaike's information criterion leads to the same conclusion about the fitting performance of the models.

[Table 7]

Additionally we have performed a Wilcoxon signed-rank test on the daily wRMSE data. The conclusions are given in Table 8 and show that the order of fitting performance (the prospect model fits better than the VF model; the VF model fits better than the WF model; the WF model fits better than the EV model; the EV model fits better than the BS model) is statistically significant.

\section{[Table 8]}

A different representation of the fitting performance of the models with the empirical option prices can be given by its implied volatility surface. Using actual option prices and determining the implied volatility of the BS model we get - on the average - the familiar smile pattern (see Figure 4), which is more pronounced the shorter the time till expiration of the option and flattens with high time till expiration of the option. In addition we can transform model predicted prices into BS model implied volatilities. From Figure 4 it is seen that the prospect, VF and WF models fit the empirical data quite well for in-the-money options. In the case of out-ofthe money options, all models underestimate the actual implied volatility at low time till expiration and overestimate the actual implied volatility at high time till expiration.

\section{[Figure 4]}

Interestingly our marginal prospect investor is risk taking in the domain of gains, risk averse in the domain of losses, loss averse and has a weighting function that favors high probabilities that the option will become in the money at expiration. This observation is different from the observations by Tversky and Kahneman (1992), as their experiments showed that deci- 
sion takers are risk avers in the domain of gains, risk taking in the domain of losses, loss averse and overestimate small probabilities. There might be two reasons for this difference. First of all, the experiments of Tversky and Kahneman are done with students and scholars and it has been observed that the financial option decisions of traders differ from decisions taken by students (Fox, Rogers and Tversky, 1996; Abbink and Rockenbach, 2005). The second reason might be that the Tversky-Kahneman data is based on the median of the estimates by the decision takers, while in the actual option trading the tails of the distribution of the subjective option values of potential investors are more important for the resulting actual option price than the average or median.

\section{Out-of-sample analysis}

The out-of-sample analysis is a measure for the forecasting performance of a model. We opt for a one (trading) day out-of-sample analysis in which the parameter values of a model are used to determine the option price of the next trading day. Table 9 shows the in-sample and out-ofsample wRMSE for the years 2002 and 2006.

\section{[Table 9]}

In line with the in-sample wRSME, the out-of-sample wRSME is lower for the low volatility year (2006) in comparison to the high volatility year (2002). In 2002 the average out-ofsample performance of the WF model is better compared to the prospect model, the prospect model performs better than the EV model, the EV model performs better than the VF model and the VF model performs better than the BS model. In 2006 the average out-of-sample performance of the prospect model is better compared to the WF model, the WF model performs better than the VF model, the VF model performs better than the BS model and the BS model performs better than the EV model.

The Wilcoxon signed-rank test of the daily wRSME of the various models is distributionfree and does capture the daily correlation of the performance of the models. The conclusions, given in Table 10, show the following statistical significant order for 2002: the out-of-sample

performance of the prospect model is better compared to the WF model, the WF model performs better than the VF model, the VF model performs better than the EV model and the EV model 
performs better than the BS model. For 2006 the order of model performance is the same as for 2002, except that the BS performs better than the EV model, but this relation is not statistically significant. We consider the results from the Wilcoxon signed-rank test as strong evidence that the incorporation of (elements of) the prospect theory into option pricing models substantially improves the out-of-sample performance of these models.

[Table 10]

The out-of-sample implied volatility surfaces are almost equal to the in-sample ones and do visually not differ from the implied volatility surfaces given in Figure 4, leading to equivalent conclusions.

\section{Conclusion}

In this paper, we study option prices in an economy where investors' decisions are conform to the behavioral aspect of the prospect theory. Our theoretical marginal prospect investor writes European call options, is risk averse in the domain of gains, risk taking and loss averse in the domain of losses, and overestimates small and underestimate large probabilities of the option expiring in-the-money. In line with recent empirical studies, we find support for non-concave

utility functions proposed by Kahneman and Tversky. Moderate prospect behavior of investors can explain the shape and size of the actual implied volatility skew, while prospect behavior based on the parameter values by Tversky and Kahneman is too severe for the actual observed implied volatility pattern.

Empirical analysis shows that incorporation of prospect theoretical elements into BlackScholes option valuation (as a pricing model) significantly improves the fitting performance of the model with European call options on the S\&P 500 index in in-sample as well as in out-ofsample analysis. Further, the analysis shows that the marginal investor's behavior is different from the prospect theoretical observations. In stead of being risk averse in the domain of gains, risk taking and loss averse in the domain of losses, and overestimate small and underestimate large probabilities of the option expiring in-the-money, marginal writers of call options on the S\&P 500 index are displaying the reverse behavior, except for loss aversion. 


\section{References}

Abbink, K.; Rockenbach, B. (2006) "Option Pricing by Students and Professional Traders: A Behavioural Investigation", Managerial and Decision Economics 27 (6) 497-510.

Barberis, N; Huang, M.; Santos, T. (2001) "Prospect Theory and Asset Prices" Quarterly Journal of Economics 116 (1) 1-53.

Bakshi, G.; Cao, C.; Chen Z. (2000) "Do call prices and the underlying stock always move in the same direction?", Review of Financial Studies 13 (3) 549-584.

Barberis, N.; Thaler, R.; (2003) "A Survey of Behavioral Finance” in Handbook of the Economics of Finance, Vol. 1B , Constantinides, G.M.; Harris, M.; Stulz, R.; (Eds), p. 1052-1121, Elsevier Science.

Benninga, S.; Mayshar, J. (2000) "Heterogeneity and Option Pricing”, Review of Derivatives Research 4 (1) 7-27.

Bernstein, P.L.; (1996) “Against the Gods: the Remarkable Story of Risk”, Wiley New York.

Black, F.; M. Scholes; (1973) “The pricing of Options and Corporate Liabilities”, Journal of Political Economy 81 (3) 637-654.

Blackburn, D.W.; Ukhov, A.D. (2006) 'Estimating Preferences towards risk: Evidence from Dow Jones', Working Paper, Kelley School of Business, Indiana University.

Breuer W.; Perst A. (2005) 'Retail Banking and Behavioral Financial Engineering', Working Paper Bfw39V5/04, RWTH Aachen.

Cox, J.C.; Ross, S.A.; Rubinstein, M. (1979) “Option Pricing: A Simplified Approach”, Journal of Financial Economics 7 (3) 229-263.

Christensen,B.J.; Prabhala, N.R. (1998) “The Relation between Implied and Realized Volatility” Journal of Financial Economics 50 (2) 125-150.

Christoffersen, P., S. Heston and K. Jacobs (2006), "Option Valuation with Conditional Skewness", Journal of Econometrics, 131 (1-2) 253-284.

Duan, J.-C. (1996), ”Cracking the Smile”, RISK 9, 55-59.

Duan, J.-C. and J.-G. Simonato (1998), "Empirical Martingale Simulation for Asset Prices", Management Science 44 (9) 1218-1233. 
Duan, J.-C. Gauthier G. and J.-G. Simonato (2001), "Asymptotic Distribution of the EMS Option Price Estimator", Management Science 47 (8) 1122-1132.

Dumas, B.; Fleming, J.; Whaley R.E. (1998) “Implied Volatility Functions: Empirical Tests" The Journal of Finance 53 (6) 2059-2106.

Fama, E. (1965) “The Behavior of Stock Market Prices” Journal of Business 38 (1) 34-105.

Fisher, K.L.; Statman, M. (1997) "Investment Advice from Mutual Fund Companies" Journal of Portfolio Management 24 (1) 9-25.

Fleming, J.; Ostdiek, B; Whaley, R.E (1995) "Predicting Stock Market Volatility: A New Measure" Journal of Futures Markets 15 (3) 265-302.

Fox, C.R.; Rogers, B.A.; Tversky, A. (1996) "Options Traders Exhibit Subadditive Decision Weights", Journal of Risk and Uncertainty 13 (1) 5-17.

Goldberg, J.; Nitzsch von, R.; (2001) "Behavioral Finance", Wiley Chichester; first published in German in 1999 by FinanzBuch Verlag München.

Groot, de, J.S.; Dijkstra, T.K. (1996) "Writing Covered Calls: Should it be Done?", SOM Research Report 96E26, University of Groningen.

Guo, C. (1998) "Option Pricing with Heterogeneous Expectations" The Financial Review 33 (4) 81-92.

Heston, S.L. and S. Nandi (2000), "A Closed-Form GARCH Option Valuation Model", The Review of Financial Studies 13 (3), 585-625.

Heynen, R., A. Kemma and T. Vorst (1994), "Analysis of the term structure of implied volatilities", Journal of Financial and Quantitative Analysis, 29, 31-56.

Howell, S.D.; Jägle, A.J. (1997) “ Laboratory Evidence on how Managers Intuitively Value Real Growth Options", Journal of Business Finance and Accounting 24 (7/8) 915-935.

Kahneman D.; Tversky A. (1979) 'Prospect Theory, An Analysis of Decision under Risk', Econometrica 47 (2), 263-291.

Kilka, M.; Weber, M. (2001) "What determines the Shape of the Probability Weighting Function under Uncertainty?” Management Science 47 (12) 1712-1726.

Lehnert, T. (2003)", "Explaining Smiles: GARCH Option Pricing with Conditional Leptokurtosis and Skewness, Journal of Derivatives, 10 (3) 27-39.

Mayhew, S. (1995) “Implied Volatility”, Financial Analysts' Journal 51 (4) 8-20. 
Miller, K.D.; Shapira, Z. (2004) “An Empirical Test of Heuristics and Biases Affecting Real Option Valuation" Strategic Management Journal 25 (30) 269-284.

Nava, A; Camerer, C.F.; Loewenstein, G.; (2005) “Adam Smith, Behavioral Economist”, Journal of Economic Perspectives 19 (3) 131-145.

Omberg, E. (1991) 'On the Theory of Perfect Hedging', Advances in Futures and Options Re-

search 5 1-29.

Poteshman, A.M.; Serbin, V. (2003) 'Clearly Irrational Financial Market Behavior: Evidence from the Early Exercise of Exchange Traded Stock Options', Journal of Finance 58 (1) 3770.

Ritchken, P. and R. Trevor (1999), "Pricing options under generalized GARCH and stochastic volatility processes", Journal of Finance 54 (1) 377-402.

Rockenbach B. (2004) "The Behavioral Relevance of Mental Accounting for the Pricing of Financial Options", Journal of Economic Behavior and Organization 53 (4) 513-527.

Rubinstein, M. (1994) “Implied Binomial Trees” Journal of Finance 49 (3) 771-818.

Shefrin, H. (2002) "Beyond Greed and Fear: Understanding Behavioral Finance and the Psychology of Investing", Oxford University Press Oxford.

Shefrin H.; Statman M. (1993) ' Behavioral Aspects of the Design and Marketing of Financial Products', Financial Management 22 (2) 123-134.

Shefrin H.; Statman M. (2000) 'Behavioral Portfolio Theory”, Journal of Financial and Quantitative Analysis 35 (2) 127-151.

Shiller, R.J.; (1999) "Human Behavior and the Efficiency of the Financial System" in Handbook of Macroeconomics Vol. 1C, Taylor, J.B.; Woodford, M.; (Eds) p. 1305-1340, Elsevier Amsterdam.

Thaler, R.H. (1980) “Towards a Positive Theory of Consumer Choice” Journal of Economic Behavior and Organization 1 (1) 39-60.

Thaler, R.H. (1985) "Mental Accounting and Consumer Choice" Marketing Science 4 (3) 199214.

Thaler, R.H. (1999) “Mental Accounting Matters” Journal of Behavioral Decision Making 12 (3) 183-206. 
Thaler, R.H., Ed. (2005) "Advances in behavioral finance" vol. 2, Russell Sage Foundation New York; Princeton University Press Princeton.

Thaler, R.H.; Johnson, E.J. (1990) "Gambling with the House Money and Trying to Break Even: The effects of Prior Outcomes on Risky Choice" Management Science 36 (6) 643-660.

Tversky A.; Kahneman D. (1981) 'The Framing of Decisions and the Psychology of Choice", Science 211 453-458.

Tversky A.; Kahneman D. (1986) "Rational Choice and the Framing of Decisions" Journal of Business 59 (4) 5251-5278.

Tversky A.; Kahneman D. (1992) 'Advances in Prospect Theory, Cumulative Representation of Uncertainty'. Journal of Risk and Uncertainty 5 (4) 297-323. 
Figure 1: Frames of the Müller-Lyer illusion

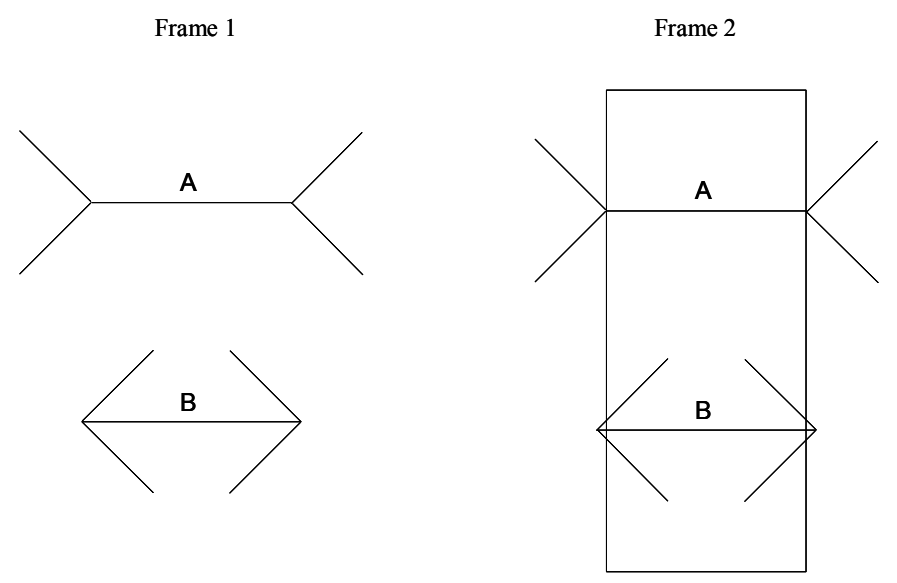


Figure 2: Implied volatility for changes in the strike price

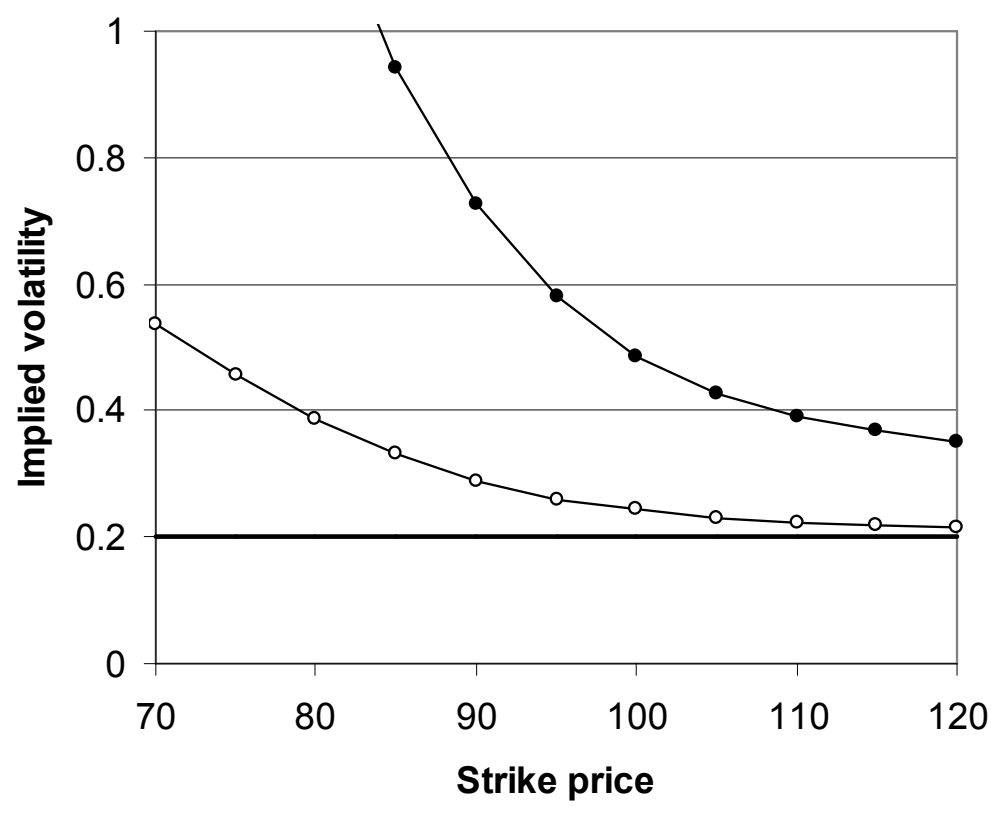

Black-Scholes reference

$\longrightarrow$ - Sentiment based on the Tversky-Kahneman parameter values - 
Figure 3: Average option price differences

(year 2002 minus year 2006)

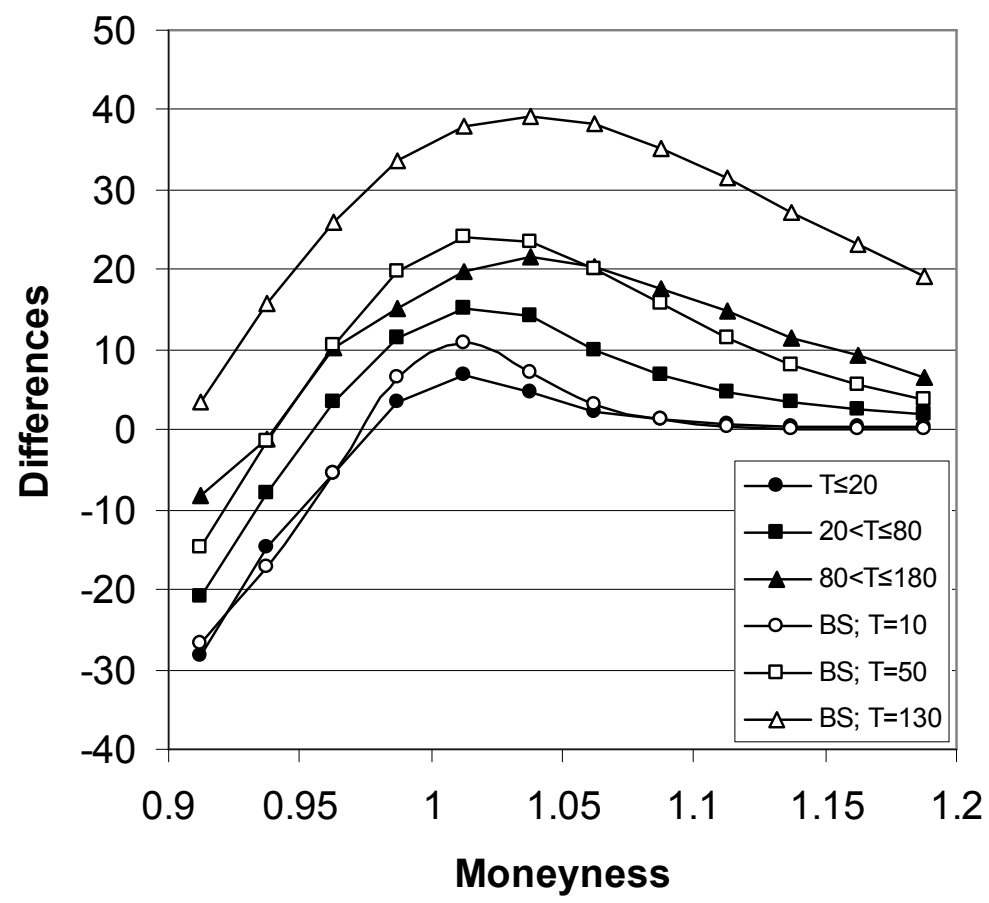


Fig 4: Average implied volatility surfaces from S\&P 500 call options
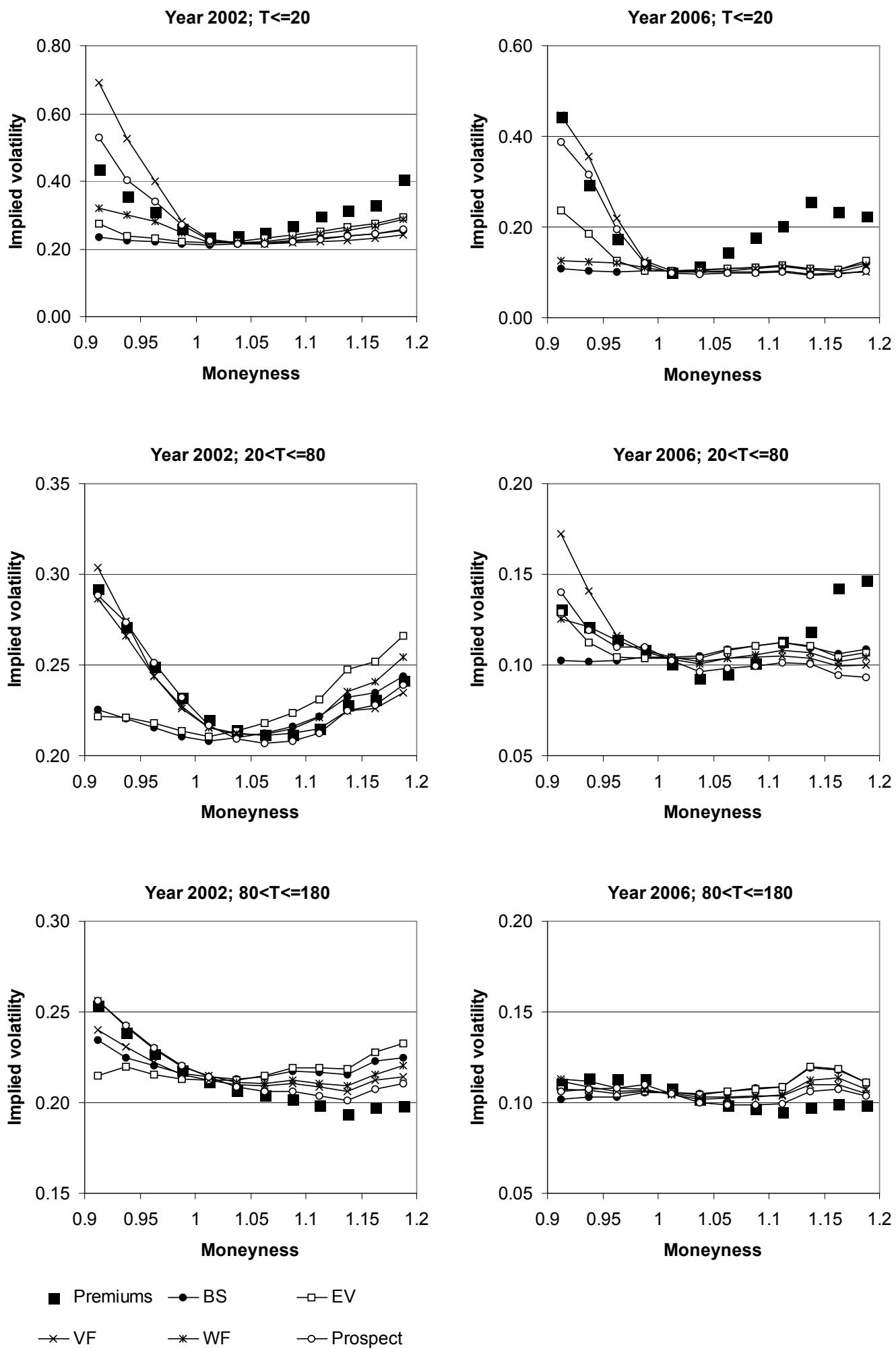
Table 1: Prospect call option prices for changes in the strike price*

\begin{tabular}{rrrrrrr}
\hline & \multicolumn{3}{c}{ Option price } & & \multicolumn{3}{c}{ (Prospect option price-BSprice)/BSprice } \\
\cline { 2 - 4 } \cline { 6 - 7 } BS & BS & $\# 1$ & & $\# 1$ & $\# 2$ \\
\hline 70 & 36.72 & 82.19 & 41.25 & & .24 & .12 \\
80 & 27.99 & 55.50 & 31.27 & .98 & .12 \\
90 & 19.99 & 35.95 & 22.20 & .80 & .11 \\
100 & 13.27 & 23.46 & 14.73 & .77 & .11 \\
110 & 8.18 & 15.69 & 9.15 & .92 & .12 \\
120 & 4.71 & 10.67 & 5.34 & & 1.27 & .13 \\
\hline
\end{tabular}

* using the following parameters: $S_{0}=100, \alpha=.1, r_{f}=.1, \sigma=.2$ and $T=1$ with BS being the Black-Scholes reference with $a=1, b=1, \lambda=1$ and $\gamma=1$, \#1 being the prospect sentiment based on the Tversky-Kahneman parameter values, $a=.88$, $b=.88, \lambda=2.25$ and $\gamma=.61$, and $\# 2$ being the moderate prospect sentiment with $a=.988, b=.988, \lambda=1.125, \gamma=.961$. 


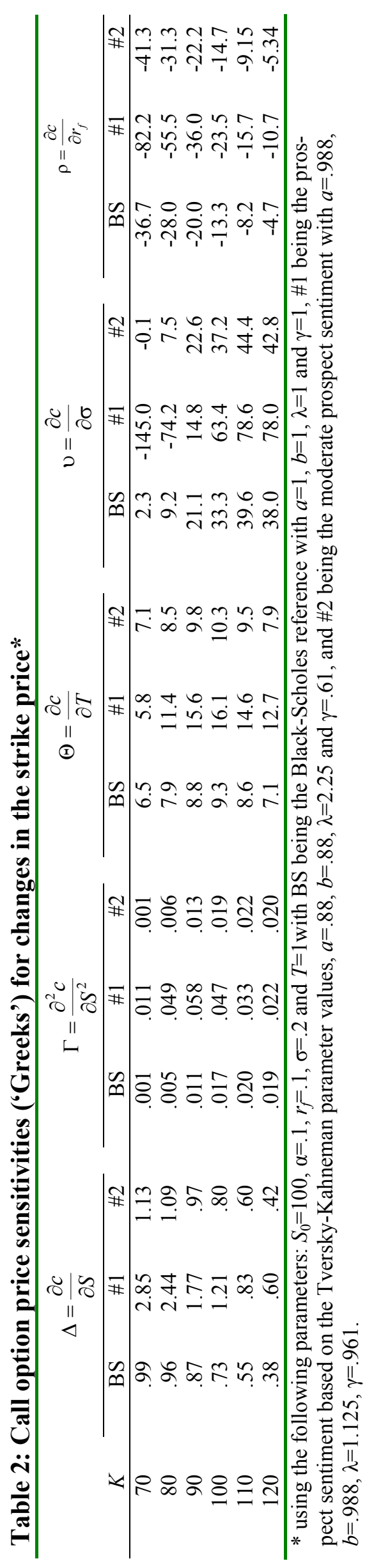




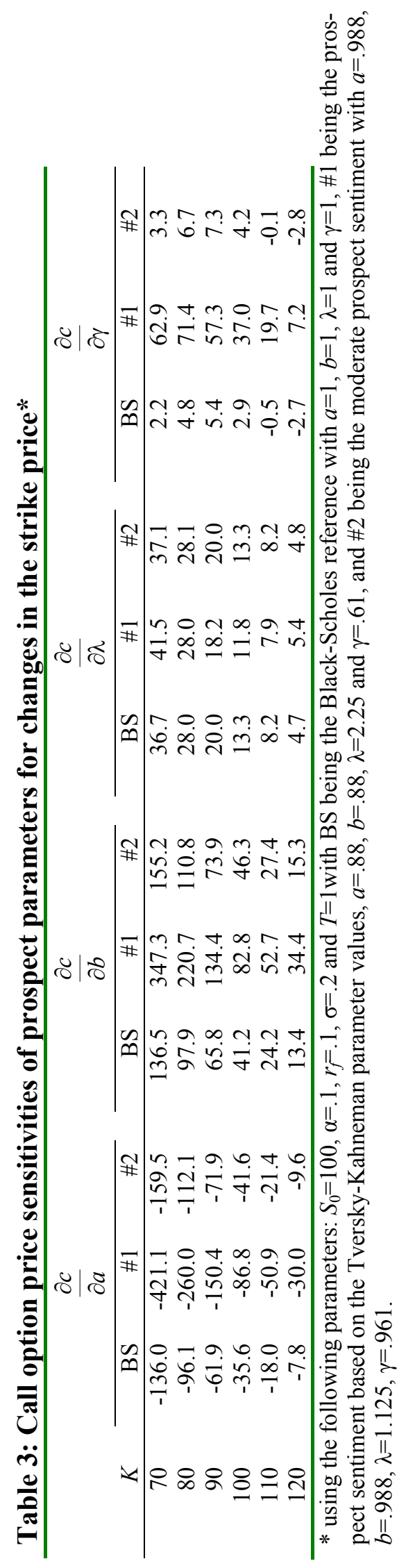




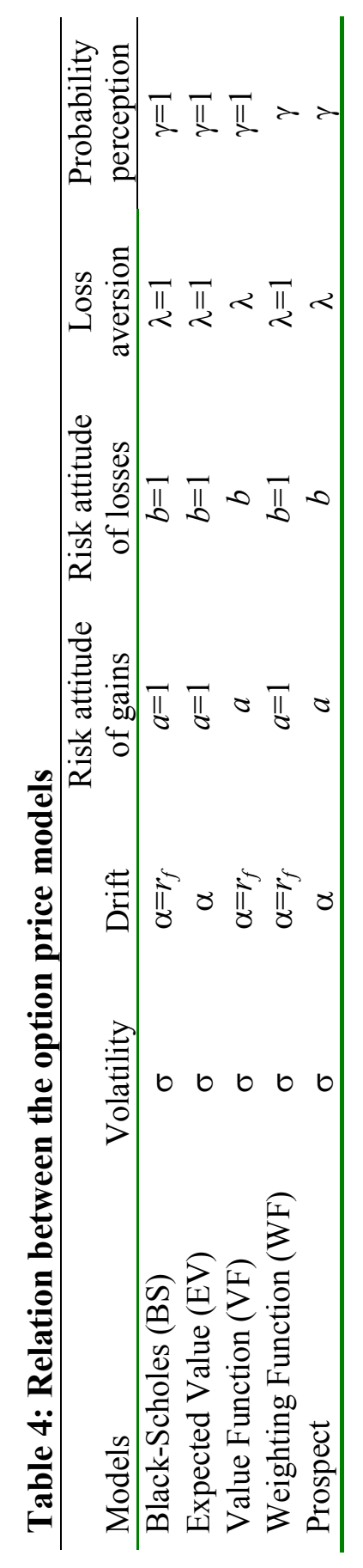


Table 5: Options data: number of observations

\begin{tabular}{lccccc} 
Year 2002 & \multicolumn{5}{l}{} \\
\hline & \multicolumn{7}{l}{ Time to expiration (trading days) } & & \\
\cline { 2 - 6 } Moneyness & $T \leq 20$ & $20<T \leq 80$ & $80<T \leq 180$ & $T>180$ & All \\
\hline$M \leq 0.9$ & 196 & 239 & 96 & 94 & 625 \\
$0.9<M \leq 0.925$ & 127 & 147 & 35 & 31 & 340 \\
$0.925<M \leq 0.95$ & 216 & 248 & 66 & 69 & 599 \\
$0.95<M \leq 0.975$ & 360 & 441 & 132 & 133 & 1066 \\
$0.975<M \leq 1$ & 601 & 759 & 229 & 244 & 1833 \\
$1<M \leq 1.025$ & 716 & 874 & 241 & 177 & 2008 \\
$1.025<M \leq 1.05$ & 636 & 736 & 196 & 147 & 1715 \\
$1.05<M \leq 1.075$ & 473 & 648 & 214 & 117 & 1452 \\
$1.075<M \leq 1.1$ & 374 & 574 & 187 & 121 & 1256 \\
$1.1<M \leq 1.125$ & 226 & 469 & 188 & 97 & 980 \\
$1.125<M \leq 1.15$ & 142 & 291 & 160 & 91 & 684 \\
$1.15<M \leq 1.175$ & 78 & 224 & 139 & 66 & 507 \\
$1.175<M \leq 1.2$ & 52 & 164 & 118 & 73 & 407 \\
$M>1.2$ & 60 & 337 & 410 & 329 & 1136 \\
\hline All & 4257 & 6151 & 2411 & 1789 & 14608 \\
\hline
\end{tabular}

\begin{tabular}{lccccc} 
Year 2006 & \multicolumn{5}{l}{} \\
\hline & \multicolumn{7}{l}{ Time to expiration (trading days) } & & \\
\cline { 2 - 6 } Moneyness & $T \leq 20$ & $20<T \leq 80$ & $80<T \leq 180$ & $T>180$ & All \\
\hline$M \leq 0.9$ & 96 & 355 & 80 & 248 & 779 \\
$0.9<M \leq 0.925$ & 95 & 162 & 68 & 168 & 493 \\
$0.925<M \leq 0.95$ & 231 & 389 & 115 & 277 & 1012 \\
$0.95<M \leq 0.975$ & 656 & 676 & 267 & 334 & 1933 \\
$0.975<M \leq 1$ & 1332 & 2021 & 423 & 230 & 4006 \\
$1<M \leq 1.025$ & 1471 & 2185 & 366 & 247 & 4269 \\
$1.025<M \leq 1.05$ & 1039 & 2089 & 344 & 247 & 3719 \\
$1.05<M \leq 1.075$ & 336 & 1105 & 292 & 183 & 1916 \\
$1.075<M \leq 1.1$ & 124 & 379 & 184 & 151 & 838 \\
$1.1<M \leq 1.125$ & 52 & 105 & 118 & 95 & 370 \\
$1.125<M \leq 1.15$ & 13 & 37 & 38 & 62 & 150 \\
$1.15<M \leq 1.175$ & 8 & 36 & 16 & 42 & 102 \\
$1.175<M \leq 1.2$ & 2 & 22 & 9 & 35 & 68 \\
$M>1.2$ & 0 & 7 & 17 & 60 & 84 \\
\hline All & 5455 & 9568 & 2337 & 2379 & 19739 \\
\hline
\end{tabular}


Table 6: Options data: average call option prices

\begin{tabular}{lccccc} 
Year 2002 & \multicolumn{7}{l}{} \\
\hline & \multicolumn{7}{c}{ Time to expiration (trading days) } \\
\cline { 2 - 6 } Moneyness & $T \leq 20$ & $20<T \leq 80$ & $80<T \leq 180$ & $T>180$ & All \\
\hline$M \leq 0.9$ & 140.04 & 195.91 & 194.86 & 213.53 & 180.88 \\
$0.9<M \leq 0.925$ & 85.03 & 93.66 & 109.57 & 145.30 & 96.79 \\
$0.925<M \leq 0.95$ & 64.46 & 74.91 & 93.24 & 126.00 & 79.04 \\
$0.95<M \leq 0.975$ & 42.38 & 57.26 & 78.63 & 108.70 & 61.30 \\
$0.975<M \leq 1$ & 24.10 & 41.21 & 64.02 & 92.77 & 45.31 \\
$1<M \leq 1.025$ & 11.30 & 28.61 & 51.16 & 78.86 & 29.57 \\
$1.025<M \leq 1.05$ & 5.18 & 18.11 & 39.58 & 67.23 & 19.98 \\
$1.05<M \leq 1.075$ & 2.47 & 11.49 & 30.32 & 52.71 & 14.65 \\
$1.075<M \leq 1.1$ & 1.27 & 7.46 & 22.34 & 45.09 & 11.46 \\
$1.1<M \leq 1.125$ & 0.71 & 5.02 & 17.14 & 40.16 & 9.83 \\
$1.125<M \leq 1.15$ & 0.47 & 3.65 & 12.77 & 34.02 & 9.17 \\
$1.15<M \leq 1.175$ & 0.37 & 2.76 & 9.91 & 27.48 & 7.57 \\
$1.175<M \leq 1.2$ & 0.29 & 2.10 & 7.06 & 20.92 & 6.68 \\
$M>1.2$ & 0.25 & 1.05 & 3.30 & 12.00 & 4.99 \\
\hline All & 22.37 & 30.97 & 38.70 & 67.14 & 34.17 \\
\hline
\end{tabular}

\begin{tabular}{lccccc} 
Year 2006 & \multicolumn{7}{l}{} \\
\cline { 2 - 6 } Moneyness & $T \leq 20$ & $20<T \leq 80$ & $80<T \leq 180$ & $T>180$ & All \\
\hline$M \leq 0.9$ & 194.54 & 174.48 & 210.90 & 185.84 & 184.31 \\
$0.9<M \leq 0.925$ & 113.20 & 114.68 & 117.67 & 135.41 & 121.87 \\
$0.925<M \leq 0.95$ & 79.19 & 83.00 & 94.53 & 109.77 & 90.77 \\
$0.95<M \leq 0.975$ & 47.96 & 53.73 & 68.36 & 86.97 & 59.54 \\
$0.975<M \leq 1$ & 20.56 & 29.81 & 48.85 & 67.84 & 30.93 \\
$1<M \leq 1.025$ & 4.32 & 13.45 & 31.24 & 51.76 & 14.05 \\
$1.025<M \leq 1.05$ & 0.60 & 4.01 & 18.02 & 35.98 & 6.48 \\
$1.05<M \leq 1.075$ & 0.13 & 1.43 & 9.96 & 24.82 & 4.73 \\
$1.075<M \leq 1.1$ & 0.07 & 0.62 & 4.85 & 20.40 & 5.03 \\
$1.1<M \leq 1.125$ & 0.06 & 0.29 & 2.40 & 15.87 & 4.93 \\
$1.125<M \leq 1.15$ & 0.03 & 0.20 & 1.20 & 10.09 & 4.53 \\
$1.15<M \leq 1.175$ & 0.08 & 0.12 & 0.66 & 7.28 & 3.15 \\
$1.175<M \leq 1.2$ & 0.05 & 0.13 & 0.37 & 5.24 & 2.79 \\
$M>1.2$ & - & 0.14 & 0.19 & 6.05 & 4.37 \\
\hline All & 20.83 & 26.02 & 41.27 & 74.05 & 32.18 \\
\hline
\end{tabular}




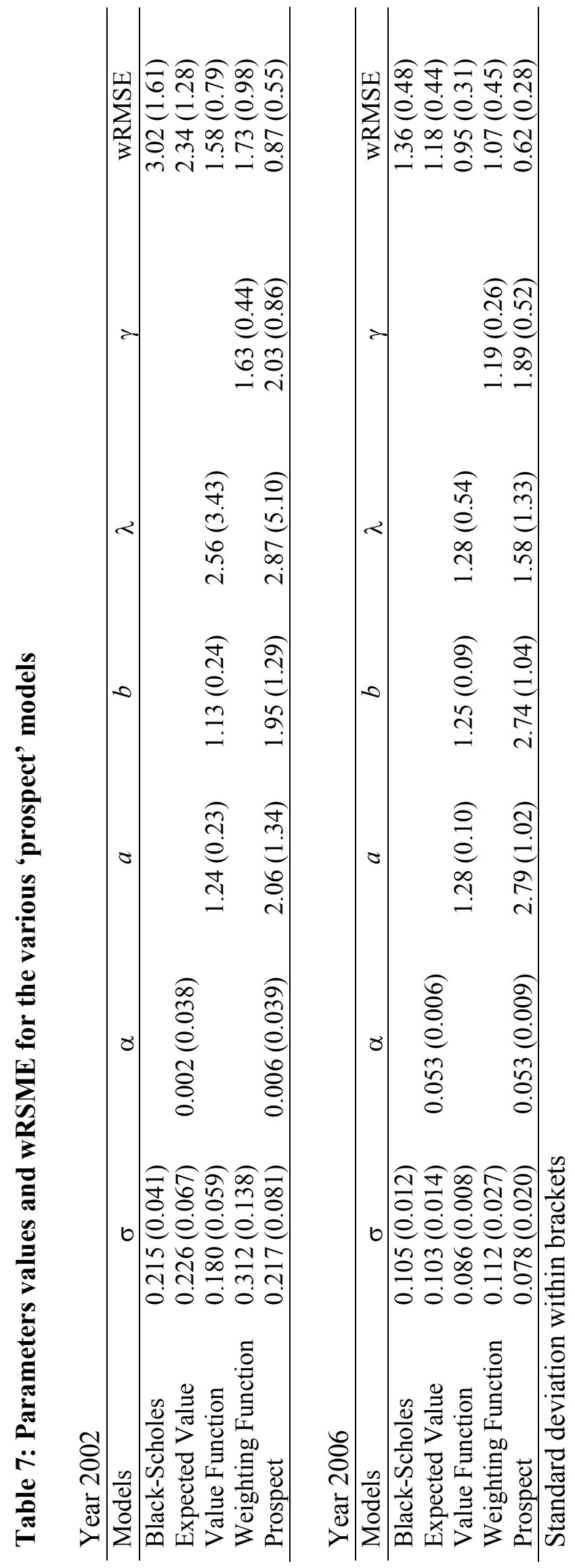


Table 8: Conclusions from the Wilcoxon signed-rank test of daily wRSME (in-sample analysis)

\begin{tabular}{|c|c|}
\hline Year 2002 & Year 2006 \\
\hline $\mathrm{wRSME}_{\mathrm{BS}}>\mathrm{wRSME} \mathrm{EV}^{* * *}$ & $\mathrm{wRSME}_{\mathrm{BS}}>\mathrm{wRSME} \mathrm{EV}^{* * *}$ \\
\hline $\mathrm{wRSME}_{\mathrm{BS}}>\mathrm{wRSME}_{\mathrm{VF}}{ }^{* * *}$ & $\mathrm{wRSME}_{\mathrm{BS}}>\mathrm{wRSME}_{\mathrm{VF}}{ }^{* * *}$ \\
\hline $\mathrm{wRSME}_{\mathrm{BS}}>\mathrm{wRSME}_{\mathrm{WF}}{ }^{* * *}$ & $\mathrm{wRSME}_{\mathrm{BS}}>\mathrm{wRSME}_{\mathrm{WF}}^{* * *}$ \\
\hline $\mathrm{wRSME}_{\mathrm{BS}}>\mathrm{wRSME}_{\text {Prospect }}{ }^{* * *}$ & $\mathrm{wRSME}_{\mathrm{BS}}>\mathrm{wRSME} \mathrm{E}_{\text {Prospect }}{ }^{* * *}$ \\
\hline $\mathrm{wRSME}_{\mathrm{EV}}>\mathrm{wRSME} \mathrm{EF}_{\mathrm{VF}}^{* * *}$ & $\mathrm{wRSME}_{\mathrm{EV}}>\mathrm{wRSME}_{\mathrm{VF}}^{* * *}$ \\
\hline $\mathrm{wRSME}_{\mathrm{EV}}>\mathrm{wRSME}_{\mathrm{WF}}^{* * *}$ & $\mathrm{wRSME}_{\mathrm{EV}}>\mathrm{wRSME}_{\mathrm{WF}}{ }^{* * *}$ \\
\hline $\mathrm{wRSME}_{\mathrm{EV}}>\mathrm{wRSME} \mathrm{E}_{\text {Prospect }}{ }^{* * *}$ & $\mathrm{wRSME}_{\mathrm{EV}}>\mathrm{wRSM} \mathrm{E}_{\text {Prospect }}{ }^{* * *}$ \\
\hline $\mathrm{wRSME}_{\mathrm{VF}}<\mathrm{wRSME}_{\mathrm{WF}}^{* *}$ & $\mathrm{wRSME}_{\mathrm{VF}}<\mathrm{wRSME}_{\mathrm{WF}}{ }^{* * *}$ \\
\hline $\mathrm{wRSME}_{\mathrm{VF}}>\mathrm{wRSME}_{\text {Prospect }}{ }^{* * *}$ & $\mathrm{wRSME}_{\mathrm{VF}}>\mathrm{wRSME} \mathrm{E}_{\text {Prospect }}{ }^{* * *}$ \\
\hline $\mathrm{wRSME}_{\mathrm{WF}}>\mathrm{wRSM} E_{\text {Prospect }}{ }^{* * *}$ & $\mathrm{wRSME}_{\mathrm{WF}}>\mathrm{wRSME}_{\text {Prospect }}{ }^{* * *}$ \\
\hline
\end{tabular}

${ }^{* * *}$ Significant at $1 \%$ level

${ }^{* *}$ Significant at $5 \%$ level 
Table 9: In-sample and out-of-sample wRSME

Year 2002

\begin{tabular}{lcc}
\hline & wRMSE & \\
\cline { 2 - 3 } Models & In-sample & Out-of-sample \\
\hline Black-Scholes & $3.02(1.61)$ & $3.57(1.91)$ \\
Expected Value & $2.34(1.28)$ & $3.07(1.61)$ \\
Value Function & $1.58(0.79)$ & $3.22(2.25)$ \\
Weighting Function & $1.73(0.98)$ & $2.46(1.31)$ \\
Prospect & $0.87(0.55)$ & $2.49(1.87)$ \\
\hline & & \\
Year 2006 & & \\
\hline & wRMSE & \\
Models & In-sample & Out-of-sample \\
\hline Black-Scholes & $1.36(0.48)$ & $1.66(0.66)$ \\
Expected Value & $1.18(0.44)$ & $1.75(0.88)$ \\
Value Function & $0.95(0.31)$ & $1.61(0.82)$ \\
Weighting Function & $1.07(0.45)$ & $1.55(0.75)$ \\
Prospect & $0.62(0.28)$ & $1.50(0.96)$ \\
\hline Standard deviation
\end{tabular}

Standard deviation within brackets 
Table 10: Conclusions from the Wilcoxon signed-rank test of daily wRSME (out-of-sample analysis)

\begin{tabular}{|c|c|}
\hline Year 2002 & Year 2006 \\
\hline $\mathrm{wRSME}_{\mathrm{BS}}>\mathrm{wRSME}_{\mathrm{EV}}{ }^{* * * *}$ & $\mathrm{wRSME}_{\mathrm{BS}}<\mathrm{wRSME} \mathrm{E}_{\mathrm{EV}}$ \\
\hline $\mathrm{wRSME}_{\mathrm{BS}}>\mathrm{wRSME}_{\mathrm{VF}}{ }^{* * *}$ & $\mathrm{wRSME}_{\mathrm{BS}}>\mathrm{wRSME}_{\mathrm{VF}}{ }^{* * *}$ \\
\hline $\mathrm{wRSME}_{\mathrm{BS}}>\mathrm{wRSME}_{\mathrm{WF}}{ }^{* * *}$ & $\mathrm{wRSME}_{\mathrm{BS}}>\mathrm{wRSME}_{\mathrm{WF}}{ }^{* * *}$ \\
\hline $\mathrm{wRSME}_{\mathrm{BS}}>\mathrm{wRSME}_{\text {Prospect }}{ }^{* * *}$ & $\mathrm{wRSME}_{\mathrm{BS}}>\mathrm{wRSME} \mathrm{E}_{\text {Prospect }}{ }^{* * *}$ \\
\hline $\mathrm{wRSME}_{\mathrm{EV}}>\mathrm{wRSME}_{\mathrm{VF}}^{* * *}$ & $\mathrm{wRSME}_{\mathrm{EV}}>\mathrm{wRSME}_{\mathrm{VF}}^{* * *}$ \\
\hline $\mathrm{wRSME}_{\mathrm{EV}}>\mathrm{wRSME}_{\mathrm{WF}}{ }^{* * *}$ & $\mathrm{wRSME}_{\mathrm{EV}}>\mathrm{wRSME}_{\mathrm{WF}}{ }^{* * *}$ \\
\hline $\mathrm{wRSME}_{\mathrm{EV}}>\mathrm{wRSME} \mathrm{E}_{\text {Prospect }}{ }^{* * *}$ & $\mathrm{wRSME}_{\mathrm{EV}}>\mathrm{wRSM} \mathrm{E}_{\text {Prospect }}{ }^{* * *}$ \\
\hline $\mathrm{wRSME}_{\mathrm{VF}}>\mathrm{wRSME}_{\mathrm{WF}}^{* * *}$ & $\mathrm{wRSME}_{\mathrm{VF}}>\mathrm{wRSME}_{\mathrm{WF}}^{* *}$ \\
\hline $\mathrm{wRSME}_{\mathrm{VF}}>\mathrm{wRSME}_{\text {Prospect }}{ }^{* * *}$ & $\mathrm{wRSME}_{\mathrm{VF}}>\mathrm{wRSME} E_{\text {Prospect }}{ }^{* * *}$ \\
\hline $\mathrm{wRSME}_{\mathrm{WF}}>\mathrm{wRSME} E_{\text {Prospect }}{ }^{* * *}$ & $\mathrm{wRSME}_{\mathrm{WF}}>\mathrm{wRSME}_{\text {Prospect }}{ }^{* * *}$ \\
\hline
\end{tabular}

${ }^{* * *}$ Significant at $1 \%$ level

${ }^{* *}$ Significant at $5 \%$ level 